\title{
IL-17 crosses the blood-brain barrier to trigger neuroinflammation: a novel mechanism in nitroglycerin-induced chronic migraine
}

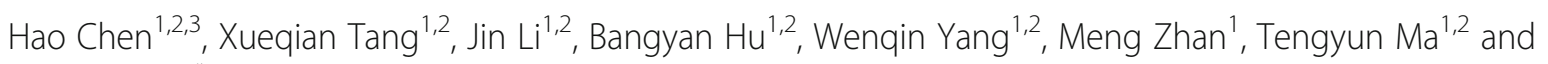
Shijun $X u^{1,2,3^{*}}$

\begin{abstract}
Background: Chronic migraine places a disabling burden on patients, which is extensively modeled by the nitroglycerin (NTG)-treated animal model. Although the NF-KB pathway is involved in an increase in CGRP levels and activation of the trigeminal system in the NTG model, the relationship between NTG and neuroinflammation remains unclear. This study aimed to optimize a chronic NTG rat model with hyperalgesia and the ethological capacity for estimating migraine therapies and to further explore the underlying mechanism of NTG-induced migraine.
\end{abstract}

Methods: Rats were administered different doses of NTG s.c. daily or every $2 \mathrm{~d} ; 30 \mathrm{~min}$ and $2 \mathrm{~h}$ later, the mechanical threshold was tested. After $9 \mathrm{~d}$, the rats were injected with EB or Cy5.5 for the permeability assay. The other animals were sacrificed, and then, brainstem and caudal trigeminal ganglion were removed to test CGRP, cFos and NOS activity; Cytokines levels in the tissue and serum were measured by ELISA; and NF-kB pathway and blood-brain barrier (BBB)-related indicators were analyzed using western blotting. Immunohistochemistry was performed to observe microglial polarization and IL-17A $\mathrm{T}$ cell migration in the medulla oblongata.

Results: NTG (10 mg/kg, s.c., every $2 \mathrm{~d}$ for a total of 5 injections) was the optimal condition, resulting in progressive hyperalgesia and migraine behavior. TNC neuroinflammation with increases in cytokines, CGRP and c-Fos and activation of the NF-KB pathway was observed, and these changes were alleviated by ibuprofen. Furthermore, NTG administration increased BBB permeability by altering the levels functional proteins (RAGE, LRP1, AQP4 and MFSD2A) and structural proteins (ZO-1, Occludin and VE-cadherin-2) to increase peripheral IL-17A permeation into the medulla oblongata, activating microglia and neuroinflammation, and eventually causing hyperalgesia and migraine attack.

\footnotetext{
*Correspondence: xushijun@cdutcm.edu.cn

'School of Pharmacy, Chengdu University of Traditional Chinese Medicine,

Chengdu, Sichuan 611137, People's Republic of China

${ }^{2}$ Institute of Meterial Medica Integration and Transformation for Brain

Disorders, Chengdu University of Traditional Chinese Medicine, Chengdu,

Sichuan 611137, People's Republic of China

Full list of author information is available at the end of the article
}

(c) The Author(s). 2021 Open Access This article is licensed under a Creative Commons Attribution 4.0 International License, which permits use, sharing, adaptation, distribution and reproduction in any medium or format, as long as you give appropriate credit to the original author(s) and the source, provide a link to the Creative Commons licence, and indicate if changes were made. The images or other third party material in this article are included in the article's Creative Commons licence, unless indicated otherwise in a credit line to the material. If material is not included in the article's Creative Commons licence and your intended use is not permitted by statutory regulation or exceeds the permitted use, you will need to obtain permission directly from the copyright holder. To view a copy of this licence, visit http://creativecommons.org/licenses/by/4.0/ The Creative Commons Public Domain Dedication waiver (http://creativecommons.org/publicdomain/zero/1.0/) applies to the data made available in this article, unless otherwise stated in a credit line to the data. 
Conclusions: This study confirmed that NTG $(10 \mathrm{mg} / \mathrm{kg}$, s.c., every $2 \mathrm{~d}$ for a total of 5 injections) was the optimal condition to provoke migraine, resulting in mechanical hyperalgesia and observable migraine-like behavior. Furthermore, IL-17A crossed the blood-brain barrier into the medulla oblongata, triggering TNC activation through microglia-mediated neuroinflammation. This process was a novel mechanism in NTG-induced chronic migraine, suggesting that IL-17A might be a novel target in the treatment of migraine.

Keywords: Nitroglycerin, Migraine, IL-17, Blood-brain barrier, Neuroinflammation

\section{Background}

Chronic migraine is a disabling neurological condition affecting up to $2 \%$ of the global population, while limited therapeutic solutions are available. The clinical characteristics of migraine include frequent headaches, hyperalgesia to visual, auditory and olfactory stimuli, nausea and vomiting, which gravely compromise the quality of life of patients [4]. Although the mechanisms of chronic migraine remain entirely unclear, it has been demonstrated that inflammation and the activation and sensitization of the trigeminal system play crucial roles in the attack. Current studies have confirmed the presence of inflammation in patients with migraine, as several major cytokines, including TNF- $\alpha, \mathrm{IL}-1 \beta$ and IL-6, are altered in patients during migraine attacks and in attack-free intervals $[13,18]$. Sterile meningeal neurogenic inflammation has been identified as an important step in patients with migraine characterized by visual aura attacks. The local inflammatory response is particularly initiated by calcitonin gene-related peptide (CGRP), pituitary adenylate cyclase-activating polypeptide (PACAP) and substance P (SP) from meningeal afferent fibers and subsequently causes vasodilatation with plasma protein extravasation and meningeal mast cell degranulation $[9,28,29,32]$. Based on the current understanding of the premonitory systems, neurogenic neuroinflammation in the brainstem, hypothalamus and parenchyma, as another trigger and amplifier, has been accepted to be crucially involved in migraine $[8,19,42]$. Recent clinical observations have also provided supporting evidence for the presence of parenchymal neuroinflammation in patients with migraine [1]. Therefore, the pathophysiological mechanisms underlying migraine pain and related to these CNS components, particularly in neurogenic neuroinflammation, provide insights into potential new antimigraine targets.

Good animal models with the characteristics of migraine are indispensable tools to elucidate pathophysiological mechanisms and identify novel therapies for chronic migraine. Nitroglycerin (NTG) has a long history of use in the clinic as a treatment for unstable angina pectoris, myocardial infarction and heart failure. The interest of neurologists and headache specialists in NTG was stimulated by one of the most frequent side effects of nitrate therapy: headache. Intravenous NTG administration frequently induces a headache with moderate intensity, and is usually accompanied by throbbing, photophobia and phonophobia, as subjects with NTGinduced headache fulfill the International Headache Society (IHS) diagnostic criteria for migraine in a very high percentage of migraineurs [41]. Although headache indeed represents an annoying side effect of NTG treatment treating angina pectoris, this characteristic might be utilized to establish a migraine-like animal model since its response to NTG parallels headaches observed in human studies, such as photophobia, phonophobia, nausea and anxiety-like behaviors [14]. Moreover, the low cost and convenient establishment of the NTG model has led to its extensive utilization in migraine research. A mouse model with chronic intermittent administration of NTG was developed to further model the migraine-like characteristics of chronic migraine (CM); this model presents acute mechanical hyperalgesia with each exposure, as well as progressive and sustained basal hyperalgesia $(1-15 \mathrm{mg} / \mathrm{kg}$, i.p.) [12, 14]. These modeling conditions were subsequently extended to other species, although the conditions lacked optimization and conversion (approximately $10 \mathrm{mg} / \mathrm{kg}$, i.p.) $[30,44]$. Moreover, i.p. NTG injection causes severe visceral pain, which limits ethological observations. Therefore, the conditions of NTG administration must be optimized and screened in common experimental species, such as rats.

Nitric oxide (NO), a small gaseous signaling molecule, and its metabolites are widely accepted as important mediators of neurogenic inflammation and neuroinflammation involved in migraine, and these processes are mainly mediated by the NO-cGMP pathways, glutamatergic pathway and NF- $\mathrm{B}$ p pathway. Therefore, NTG, a NO-donating agent, has been recognized as a translational model that has been strongly implicated in the pathological mechanisms of migraine [22]. In human subjects, NTG-induced migraine is associated with an increase in the plasma CGRP concentration [27]; increased levels of CGRP, SP and PACAP were also reported in the plasma of rodents treated systemically with NTG [7, 26, 29]. Abundant reports have indicated that neurogenic inflammation caused by NTG-induced neural activation leads to migraine-like behavior and an increased sensitivity to pain in an NTG model. NO 
released from NTG initiate a rather slow process that likely involves the activation of the trigeminovascular system in the dura mater and the subsequent activation of trigeminal fibers and the trigeminal nucleus caudalis (TNC) [22]. Furthermore, the NTG-induced increase in NOS activity is implicated in higher basal CGRP levels and might activate the exudation of blood material synergistically, leading to neurogenic inflammation involving the NF-kB pathway [33, 54]. NTG-induced iNOS expression is also accompanied by an increase in NF- $\mathrm{kB}$ activity and levels of cytokines, such as TNF- $\alpha$, IL- 6 and IL-1 $\beta$ [18]. On the other hand, although neurogenic neuroinflammation is highly relevant to migraine, the underlying mechanisms by which NTG modulates this response are unclear. Neuroinflammation extensively involves blood-brain barrier (BBB) disruption in patients with multiple sclerosis, systemic lupus erythematosus and traumatic brain injury, in which CGRP and NO play pivotal roles [17, 38, 45, 49]. The medulla oblongata (MO) is one of the vital components in trigeminal nerve signal transduction from the TNC and contains a special $\mathrm{BBB}$ for sensing brain biochemical interactions, including $\mathrm{NO}, \mathrm{O}_{2}$ and cytokines [52]. Although the $\mathrm{MO}$ has been reported to be activated during migraine attack, the trigger of $\mathrm{MO}$ activation remains unknown [43]. Some recent studies have suggested that microglial inflammatory polarization is involved in neuroinflammation of the MO [55] and NTG-induced migraine [36]. This evidence suggests that NTG-induced migraine is probably associated with alterations in blood-brain barrier (BBB) permeability induced by neuroinflammation and the vasodilatory effects of NO and CGRP. The mechanism of neuroinflammation must be investigated in NTG-administered model to reveal the possible mechanisms underlying the pathophysiology of migraine and to discover novel targets for identifying possible therapeutic strategies for migraine.

Therefore, this study aimed to optimize and screen NTG treatment conditions in order to establish a chronic migraine rat model with hyperalgesia and test the ethological capacity for assessing novel migrainepreventive therapies. Mechanistically, the effect of NTG on the $\mathrm{BBB}$ in the MO region was observed, and we subsequently explored the underlying mechanism of neuroinflammation induced by NTG-mediated BBB alteration.

\section{Methods}

\section{Animal preparation}

The adult male SPF-grade Sprague-Dawley rats (200 \pm $20 \mathrm{~g})$ used in the study were provided by the Experimental Animal Center at Byrness Weil Biotech Ltd. (Chongqing, China) and were maintained in plastic cages at $22 \pm 2{ }^{\circ} \mathrm{C}$ on a $12 \mathrm{~h}$ light/dark cycle with free access to food and water in the Experimental Animal Center at
Chengdu University of Traditional Chinese Medicine (Chengdu, China). The animal approval number provided by the Ethics Committee for Animal Experiments of the Institute of Materia Medica Integration and Transformation for Brain Disorders was IBD2020005. All studies were strictly performed in accordance with the international ethical guidelines and related ethical regulations of the IRB of the Institute of Materia Medica Integration and Transformation for Brain Disorders, Chengdu University of Traditional Chinese Medicine.

\section{Chemical reagents and antibodies}

Nitroglycerin injection was purchased from Beijing Yimin Pharmaceutical Co., Ltd. (Beijing, China). DMSO, PBS and sodium dodecyl sulfate polyacrylamide gel kits were obtained from Solarbio (Beijing, China). Primary antibodies, including anti-c-Fos, anti-NF-kB p65, antiNF- $\kappa B$ p-p65, anti-RAGE, anti-LRP1, anti-AQP4, antiMFSD2A, anti-ZO-1, anti-Occludin, anti-VE-cadherin-2, anti- $\beta$-actin, and anti-Iba1, were furnished by Cell Signaling Technology (Beverly, MA, USA). anti-iNOS and anti-IL-17A antibodies were purchased from Abcam (Shanghai, China). Anti-fitc- $\mathrm{CD}_{4}$, Anti-alexa fluor 488rabbit IgG, anti-cy3-mouse IgG, anti-mouse IgG and anti-rabbit IgG secondary antibodies were purchased from ABclonal (Wuhan, China).

\section{NTG administration}

NTG injection was prepared as a stock solution of 5.0 $\mathrm{mg} / \mathrm{mL}$. The vehicle control used in these experiments was $0.9 \%$ saline. NTG was freshly diluted in $0.9 \%$ saline to a series of predefined doses. All injections were administered at a $10 \mathrm{~mL} / \mathrm{kg}$ volume. Unless indicated otherwise, animals were tested for baseline mechanical threshold responses immediately prior to the subcutaneous (s.c.) injection of NTG. The positive groups were orally administered ibuprofen $30 \mathrm{~min}$ before NTG injection. All groups were tested for the mechanical threshold $30 \mathrm{~min}$ or $2 \mathrm{~h}$ after NTG injection. For chronic experiments, testing occurred daily or every second day ( 5 test days total) for $9 \mathrm{~d}$. Similarly, for the positive experiment, all rats were orally administered ibuprofen or vehicle every second day for $9 \mathrm{~d}$ (a detailed time schedule is shown in Fig. 1).

\section{Mechanical threshold test}

The mechanical threshold for responses to punctate mechanical stimuli (mechanical hyperalgesia) was tested as described previously [21, 47]. Briefly, the plantar surface of the animal hindpaw was stimulated with electronic von Frey filaments (bending force ranging from 0 to $80 \mathrm{~g}$ ), and the withdrawal threshold was measured by recording the instant withdrawal of the paw upon applying pressure from the tip. The average withdrawal 


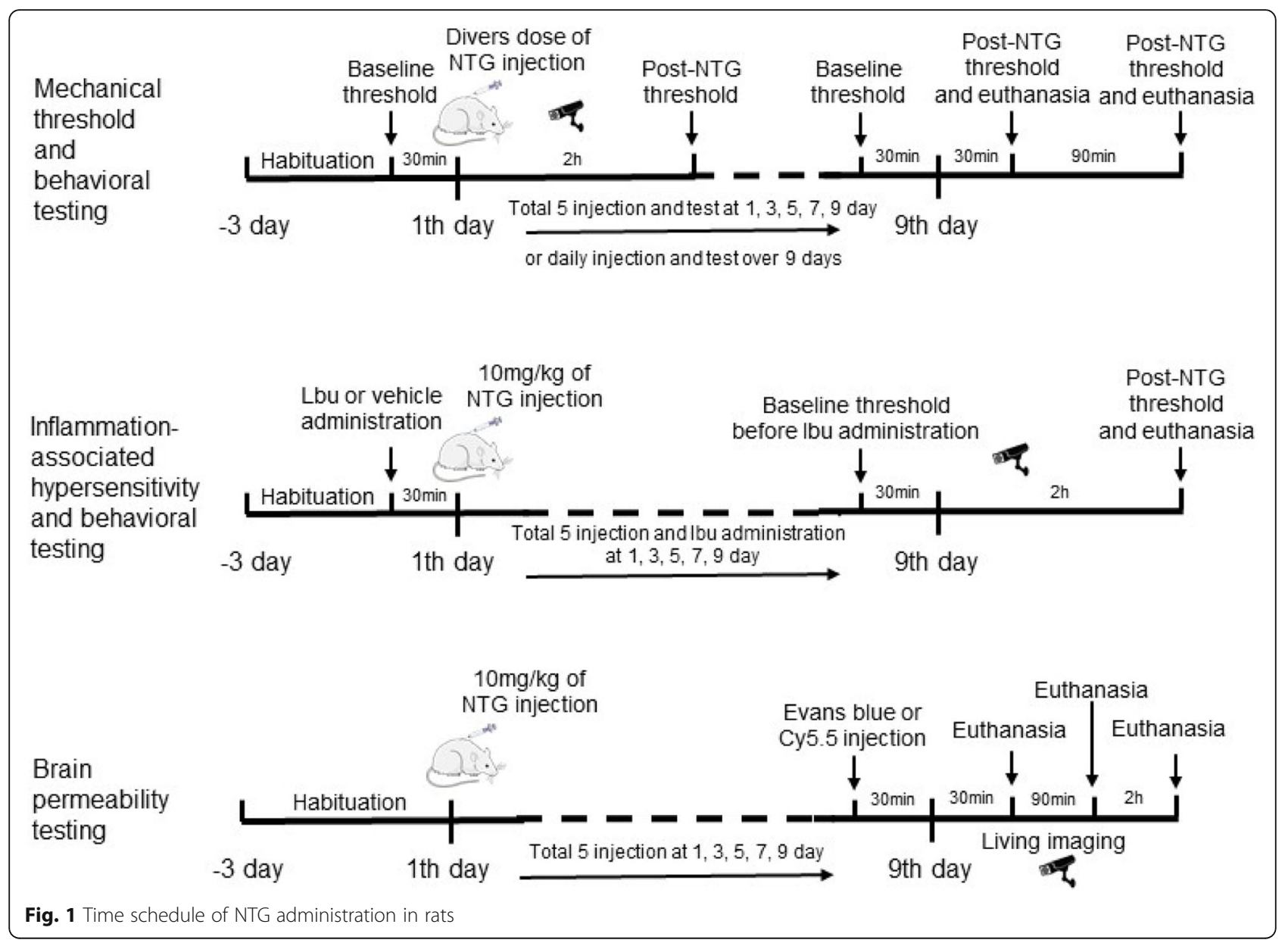

reading of a minimum of three trials was recorded as the final value. Similarly, the tail surface was stimulated with an electronic analgesy-meter (bending force ranging from 0 to $600 \mathrm{~g}$ ), and the response was defined as lifting or shaking of the tail or vocalization upon stimulation.

\section{Migraine-like behavioral test}

The latency of ear redness, frequency of head scratching and number of cage-climbing events were measured in cubicles with a video camera (Epcbook, China) placed away from the cubicle in positions facing the subject. Briefly, before NTG injection, all rats were habituated to the cubicles for $30 \mathrm{~min}$. Migraine-like behaviors were recorded over a 2-h NTG test period. Scratching and climbing behaviors and latency of ear redness were quantified based on the observations of the defined events (for details, see ML Chanda et al. [10], W Wen et al. [53]) in a blinded manner and counted by two colleagues from a digital video. The analysis of head scratching and cage climbing was valid only if the discrepancy between the two observers was less than $10 \%$ to avoid discrepancies between the two observers.

\section{Elisa}

On the 9th day, half of the rats were sacrificed $30 \mathrm{~min}$ after NTG administration, and their serum, TNC and TG were collected. Then, the other rats were sacrificed $2 \mathrm{~h}$ after NTG administration, and serum and tissues were collected in the same manner. The CGRP content and NOS activity in tissues and the IL-17A, TNF- $\alpha$, IL-6 and IL-1 $\beta$ contents in serum and tissues were determined using enzyme-linked immunosorbent assay (ELISA) kits (MultiSciences, China) according to the manufacturer's instructions.

\section{qRT-PCR analysis}

The mRNA samples were prepared and qRT-PCR was conducted as described previously [20]. Briefly, TNC and TG were collected in TRIzol (Invitrogen Life Technologies), and total RNA was extracted according to the manufacturer's instructions. RNA samples were treated with RNase-free DNase I (Roche) to remove DNA contamination. The cDNA templates were produced from mRNA samples using the RevertAid First Strand cDNA Synthesis Kit (Thermo Scientific, USA). Quantitative determination of gene expression was performed using a 
Chromo 4 Detector (Bio-Rad, USA) with a two-step cycling protocol. Hypoxanthine-guanine phosphoribosyltransferase (HPRT) was used to normalize gene expression. qRT-PCR was conducted with cDNAs in duplicate $15 \mu \mathrm{L}$ reactions using Maxima SYBR Green/ ROX qPCR Master Mix (2X) (Thermo Scientific, USA). The reactions were incubated at $50^{\circ} \mathrm{C}$ for $2 \mathrm{~min}$ and then at $95^{\circ} \mathrm{C}$ for $10 \mathrm{~min}$. A polymerase chain reaction cycling protocol consisting of $15 \mathrm{~s}$ at $95^{\circ} \mathrm{C}$ and $1 \mathrm{~min}$ at $60^{\circ} \mathrm{C}$ for 45 cycles was used for quantification. The relative expression levels were calculated according to the method described by Livak and Schmittgen34, and values were normalized to respective normal samples. The sequences of the primers used for qRT-PCR experiments were as follows: IL-17A, 5'-CTCAGACTACCT CAACCGTTCC-3' and 5' -GTGCCTCCCAGATCACAGAAG-3'; $\alpha$-CGRP, $5^{\prime}$-CCTGGTTGTCAGCATCTT GC-3' and 5'-CACATTGGTGGGCACAAAG-3'; and NF-kB p65, 5'-GTACTTGCCAGACACAGACGA-3' and 5' -CTCGGGAAGGCACAGCAATA-3'.

\section{Protein preparation and western blot analysis}

Protein preparation and western blotting were conducted as described previously [53]. Briefly, the MO with TNC was collected and lysed in RIPA buffer containing phenylmethanesulfonyl fluoride and PhosSTOP (Solarbio, China). The supernatant containing proteins was collected and stored at $-80^{\circ} \mathrm{C}$ until use. Protein concentrations were measured with a BCA kit (Beyotime, China). Equivalent amounts of the proteins were separated on SDS-PAGE gels and transferred to polyvinylidine difluoride membranes (Bio-Rad, USA). The membranes were blocked with $5 \%$ skim milk in Trisbuffered saline containing Tween $20(0.5 \%)$ for $2 \mathrm{~h}$. Subsequently, the membranes were incubated with the primary antibody at $4{ }^{\circ} \mathrm{C}$ overnight and incubated with the secondary antibody at $37^{\circ} \mathrm{C}$ for $2 \mathrm{~h}$. The HRP ECL system (Beyotime, China) was used to visualize the protein bands, and the gray values were then analyzed.

\section{Immunohistochemistry (IHC) analysis}

Immunohistochemical staining was conducted as described previously [11]. Briefly, after embedding tissues in paraffin, the MO with TNC was cut into sections $(5 \mu \mathrm{m})$, incubated with the designated primary antibodies, and visualized by incubating sections with the corresponding secondary antibodies before capturing images at a magnification of $200 \times / 400 \times$ by confocal microscopy (Olympus, Japan).

\section{Live imaging}

Live imaging was conducted as described previously [48]. Briefly, $200 \mu \mathrm{L}$ of nonpenetrating fluorescent dyeloaded Cy5.5 (US Everbright, China) solution was injected into the tail vein of rats 30 min before NTG administration to determine the permeability of the brain. Fluorescence images of the rat brain were captured $4 \mathrm{~h}$ after NTG administration using an in vivo imaging system (Clairvivo OPT, SHIMADZU Corporation, Japan). Rats were fixed in dorsal positions to acquire optical images of the head.

\section{Evans blue assay}

The Evans blue assay was conducted as described previously [2]. Briefly, a 4\% Evans blue staining solution (Sigma-Aldrich) was freshly prepared and intravenously injected $(4 \mathrm{~mL} / \mathrm{kg})$ into the tail vein of rats $30 \mathrm{~min}$ before NTG administration. Animals were euthanized $30 \mathrm{~min}$ and $2 \mathrm{~h}$ after the Evans blue injection. They were deeply anaesthetized and transcardially perfused with $4 \%$ paraformaldehyde. Images of the brain were captured using a digital camera (Olympus SZX16, Japan). TNC sections were frozen in OCT and photographed using a confocal microscope (Olympus, Japan).

\section{Statistical analysis}

All data are presented as the means \pm SD from three independent experiments. All data were determined to have a normal distribution using the Shapiro-Wilk test and statistically significant differences were analyzed using one-way analysis of variance (ANOVA) for multiple comparisons, and $p$ values $<0.05$ were considered significant.

\section{Results}

Optimization of conditions for NTG-induced migraine in rats

Mechanical threshold of rats with migraine induced by the administration of different doses of NTG for different periods

Based on the Meeh-Rubner formula and the literature $[15,40]$, the NTG equivalent dose for rats is $7 \mathrm{mg} / \mathrm{kg}$, i.p., every $2 \mathrm{~d}$. Unexpectedly, in the preliminary test, NTG-administered rats showed persistently crouched, spraining bodies and insensitive behavior after the first intraperitoneal injection of NTG, which impeded the ethological observation of the mechanical pain threshold. Therefore, subcutaneous injection was alternatively applied to deliver NTG because of its relatively mild irritation recorded in some migraine studies. We screened and optimized the modeling conditions by administering different dose doses $(0-15 \mathrm{mg} / \mathrm{kg})$ of NTG daily or every $2 \mathrm{~d}$ for $9 \mathrm{~d}$, resulting in a total of 9 or 5 NTG injections/ test days. Repetitive intermittent NTG administration over 9 days produced significant time- and dosedependent chronic basal mechanical hyperalgesia, as assessed by testing prior to each administration of NTG (Fig. 2A). In addition, NTG evoked significant acute 
A

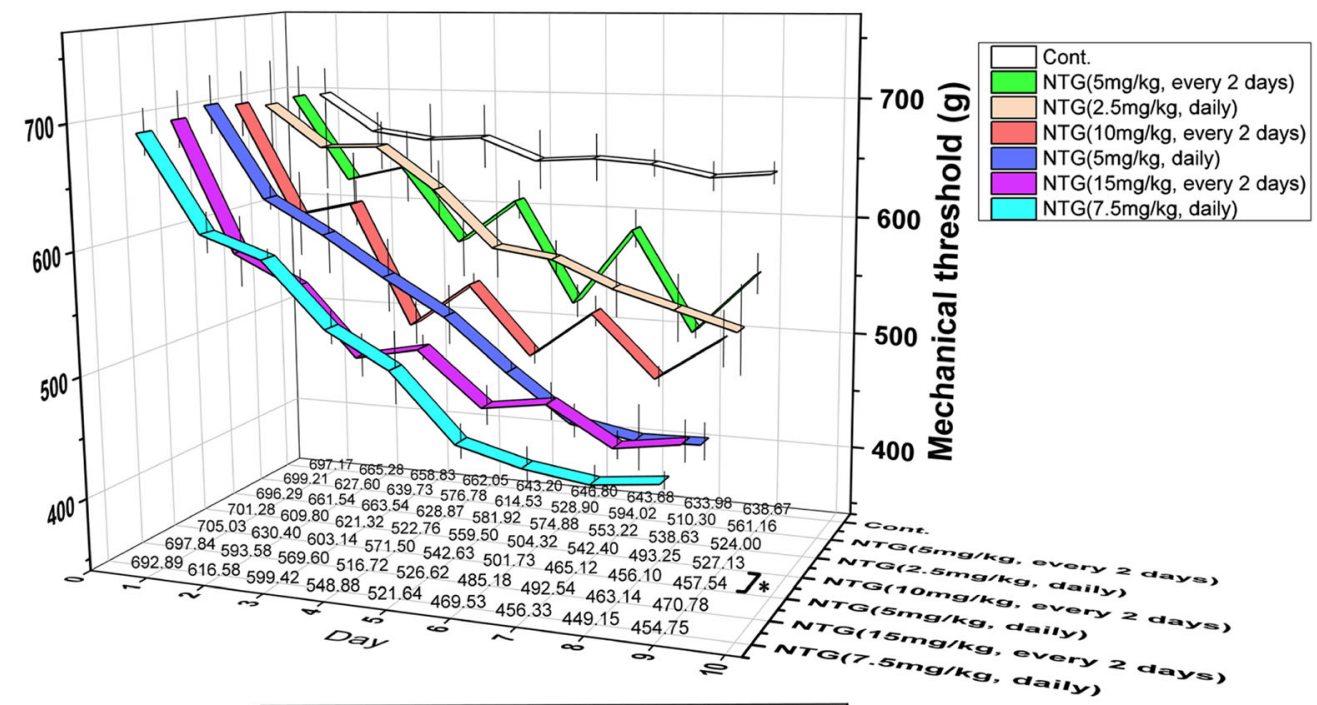

B

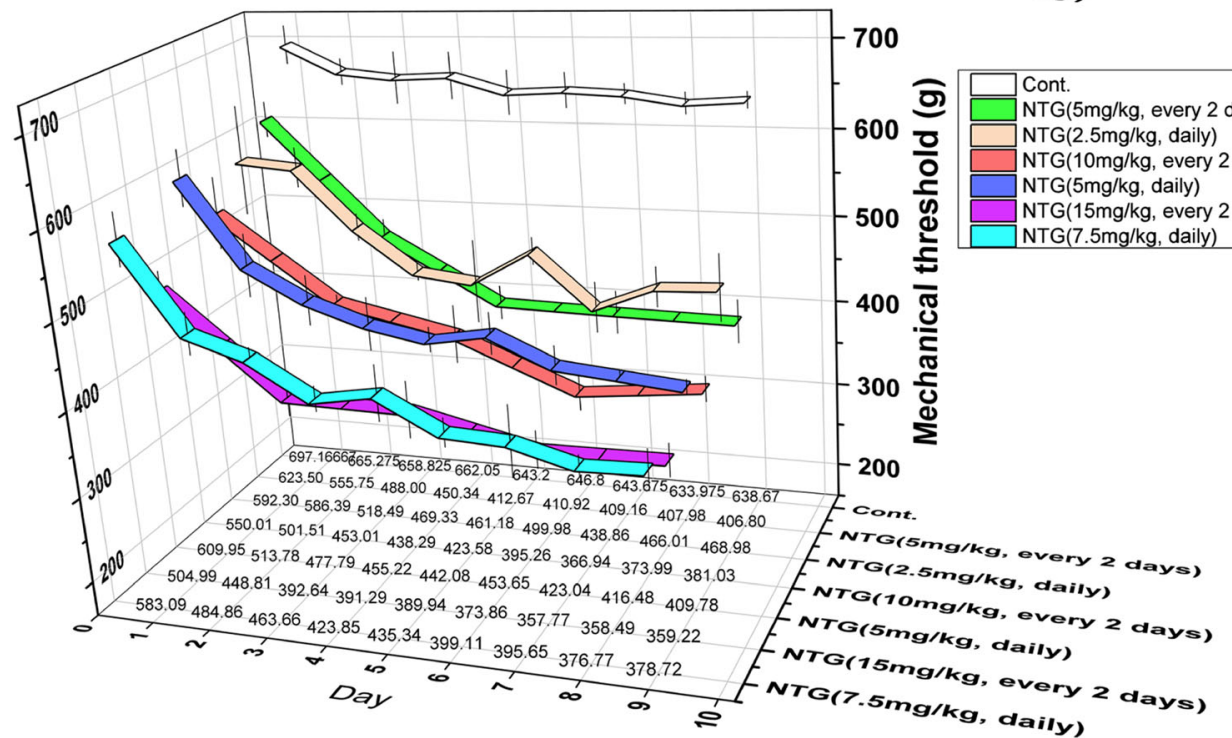

C NTG(2.5mg/kg, daily)

D $\quad \mathrm{NTG}(5 \mathrm{mg} / \mathrm{kg}$, daily)

E NTG(7.5mg/kg, daily)

$\mathrm{F} \quad$ 9th day

Do 8007 Cont.- Basal NGG(2.25g/kg, daily)

$\rightarrow$ Cont. $\rightarrow$ Basal NTG(5mg/kg, daily)

- Post-treated NTG(5mg/kg, daily)

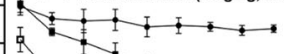

I

1

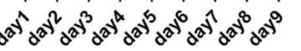

G NTG(5mg/kg, every 2 days)

$\mathrm{H}$ NTG(10mg/kg, every 2 days)

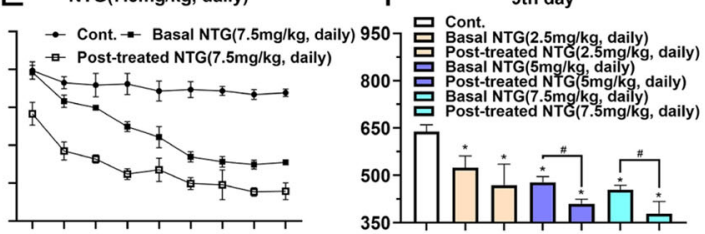

可 8007 - Cont.- Basal NTG(5mg/kg, even,

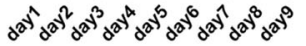

I NTG(15mg/kg, every 2 days) J

ays - Cont. - Basal NTG(10mg/kg, every 2 days) $7^{\circ-~ C o n t . ~ * ~ B a s a l ~ N T G(15 m g / k g, ~ e v e r y ~} 2$ days)
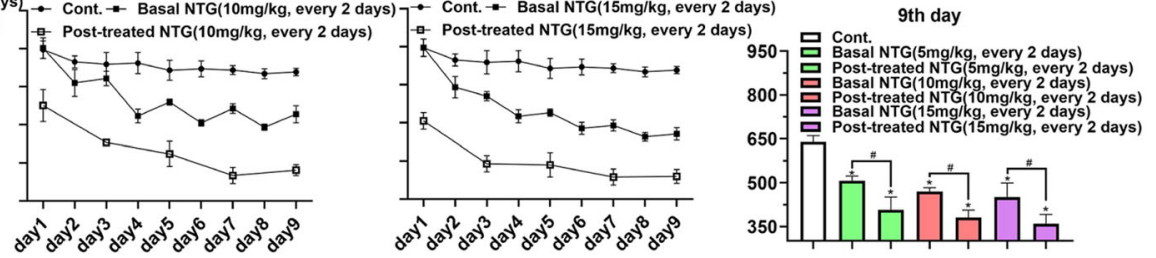

Fig. 2 (See legend on next page.) 
(See figure on previous page.)

Fig. 2 Analysis of the mechanical threshold of rats with NTG-induced migraine. Multiple NTG administrations evoked and sustained mechanical hyperalgesia. Rats were treated every $2 \mathrm{~d}$ with varying doses of NTG $(0,2.5,5$ and $7.5 \mathrm{mg} / \mathrm{kg}$, s.c., daily or $0,5,10$ and $15 \mathrm{mg} / \mathrm{kg}$, s.c., every $2 \mathrm{~d})$ for 9 d. (A) Basal mechanical threshold of all groups during NTG administration. (B) Posttreatment NTG mechanical threshold of all groups during NTG administration. (C-E) Mechanical threshold of the rats with migraine administered NTG s.c. daily for $9 \mathrm{~d}$. (F) Mechanical threshold of the rats administered consecutive NTG s.c injections on the 9th day. (G-I) Mechanical threshold of the rats with migraine administered NTG s.c. every $2 \mathrm{~d}$ for $9 \mathrm{~d}$. (J) Mechanical threshold of the rats s.c. administered intermittent NTG on the 9th day. Each dose group was significantly different from the vehicle group $(p<0.05)$, and each dose also produced significantly different results from the other doses $(p<0.05)$. NTG produces dosedependent and persistent hyperalgesia in rats. Statistical analysis was performed using one-way ANOVA, $n=6,{ }^{*} p<0.05$ compared to the basal mechanical threshold

mechanical hyperalgesia in a dose-dependent manner on each test day (Fig. 2B). The greatest decreases in basal and posttreatment responses were observed in animals injected with $10 \mathrm{mg} / \mathrm{kg}$ NTG every $2 \mathrm{~d}$ (Fig. 2C-J). Thus, $10 \mathrm{mg} / \mathrm{kg}$ NTG was utilized in subsequent experiments.

\section{Migraine-like behaviors of rats with migraine after administration of different doses of NTG for different periods}

During migraine experiences, migraine-like behaviors of rats, such as head scratching and climbing, were exacerbated as a result of nociception, which has been extensively used to assess rodent migraine models. The results of behavioral tests indicated that the latency of ear redness was significantly shortened, while no difference was observed among the majority of groups (Fig. 3A). The number of head scratches was obviously increased within $120 \mathrm{~min}$ after NTG administration in the majority of groups. Similarly, the number of cageclimbing instances was also increased, especially after the administration of $10 \mathrm{mg} / \mathrm{kg}$ NTG every $2 \mathrm{~d}$. The NTG administration group showed a prominent increase in this behavior, while the highest dose group exhibited insensitivity to cage climbing, similar to rats s.c. with NTG (Fig. 3B and C).

\section{Migrainous mediator of migraine in rats treated with different doses of NTG for different times}

Since CGRP, c-Fos and NOS are potent indicators of NTG-induced migraine, qRT-PCR was employed to measure the levels of the CGRP transcript in the TNC and TG. ELISA was used to monitor CGRP and NOS levels. Western blotting was employed to assess c-Fos expression on the 9th day. The qRT-PCR results indicated that various NTG administration protocols increased CGRP transcript levels in the TNC and TG (Fig. 4A and B). As predicted, the ELISA results revealed that NTG administration increased NOS levels in the TNC, while only $7.5 \mathrm{mg} / \mathrm{kg}$ daily and 10 and $15 \mathrm{mg} / \mathrm{kg}$ every $2 \mathrm{~d}$ groups showed significant increases in CGRP levels, especially in the $10 \mathrm{mg} / \mathrm{kg}$ every $2 \mathrm{~d}$ group at $2 \mathrm{~h}$ (Fig. 4C and D). Western blot results revealed that NTG induced c-Fos activation in the TNC (Fig. 4E). Altogether, $10 \mathrm{mg} / \mathrm{kg}$ NTG administered every $2 \mathrm{~d}$ is the most optimized modeling condition for chronic migraine in rats with mechanical hyperalgesia and ethological capacity.

NTG-induced migraine is triggered by Neuroinflammation in the TNC

NTG induced neuroinflammation in the TNC and promoted microglial inflammatory polarization

Recent evidences suggest that neuroinflammation plays a pivotal role in migrainous hyperalgesia $[18,29]$. The levels of the cytokines TNF- $\alpha$, IL- 6 and IL- $1 \beta$, and NF$\kappa B$ p65, an inflammation-related activated marker, were detected at $30 \mathrm{~min}$ and $2 \mathrm{~h}$ after NTG injection to investigate whether the TNC showed neuroinflammation hallmarks in the NTG administration model. The ELISA results showed that NTG increased the levels of inflammatory cytokines. The TNF- $\alpha$ and IL- 6 levels were rapidly increased at $30 \mathrm{~min}$, and the IL- $1 \beta$ level was subsequently increased at $2 \mathrm{~h}$ (Fig. 5A-C). The qRTPCR results showed substantially increased levels of the $\mathrm{NF}-\mathrm{kB}$ p 65 transcript in the TNC at $30 \mathrm{~min}$ that persisted for $2 \mathrm{~h}$ compared to levels of the NF-kB p65 transcript in the TG (Fig. 5D and E). Western blot data further revealed that NTG increased NF-kB p65 expression and phosphorylation in the TNC, and this activation occurred sooner than the increase in CGRP levels (Fig. 4C; Fig. 5F and G), suggesting that NTG-induced hyperalgesia may be associated with inflammation in the TNC. TNC immunohistochemical staining also revealed that microglia, which function in immune surveillance and responses, were enriched in the TNC and its iNOS and NF- $\mathrm{kB}$ p65 were activated, suggesting that neuroinflammation was activated by microglia (Fig. 6).

\section{Inhibiting neuroinflammation in the TNC alleviated NTG- induced hyperalgesia and migraine-like behaviors}

Clinically, ibuprofen is extensively applied to relieve migraine symptoms due to its anti-inflammatory activity. Thus, ibuprofen was employed to treat NTG-induced inflammation and migraine. As expected, ibuprofen treatment reversed the increase in CGRP levels and activation of NF- $\kappa B$ signaling in the TNC (Fig. 7A-C). Ethological observations further confirmed that ibuprofen alleviated NTG-induced mechanical hyperalgesia 


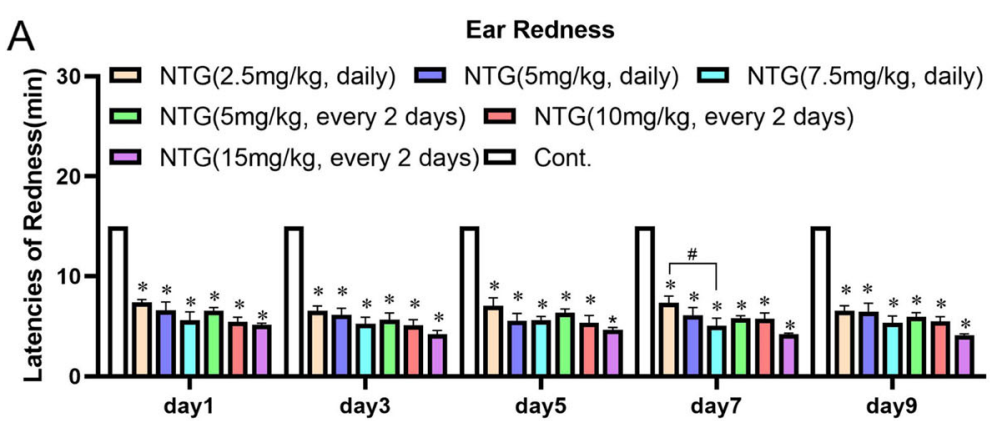

B

Head scratching

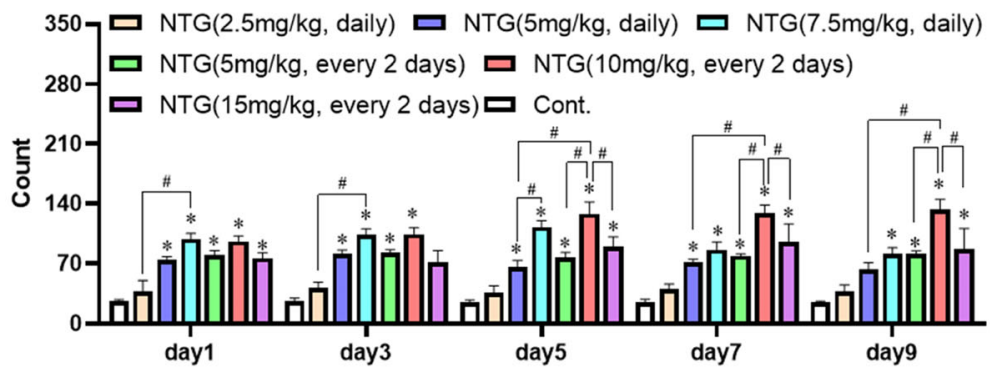

C

Cage climbing

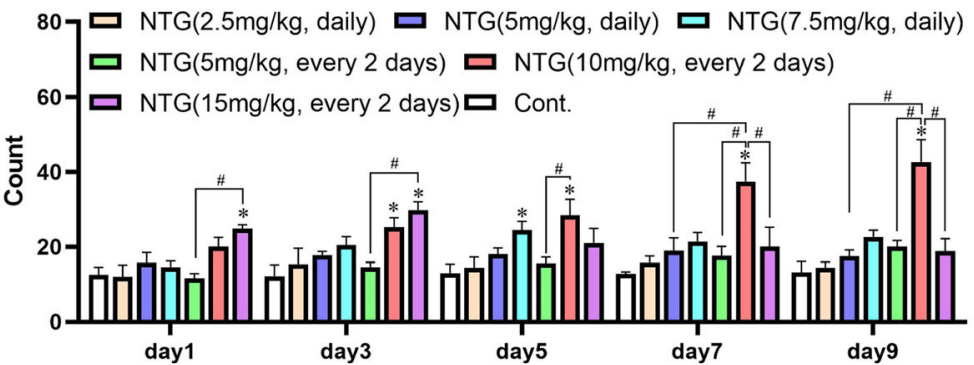

Fig. 3 Migraine-like behaviors of rats with NTG-induced migraine. (A) Latency of ear redness in rats with NTG-induced migraine. (B) Frequency of head scratching in rats with NTG-induced migraine. (C) Number of cage climbing instances recorded for rats with NTG-induced migraine. The statistical analysis was performed using one-way ANOVA, $n=6,{ }^{*} p<0.05$ compared to the control group, and ${ }^{*} p<0.05$ compared to the indicated group

(Fig. 7D) and migraine-like behavior (Fig. 7E, F and G). Based on these results, migraine symptoms in the NTGadministered model were induced by neuroinflammation in the TNC. The results that ibuprofen blocked NTGinduced inflammation were also supported by several previously reported findings, suggesting that the NTGinduced rat model could be utilized to evaluate migraine drugs with antiphlogistic activity.

Latency of ear redness in rats with NTG-induced migraine. (B) Frequency of head scratching in rats with NTG-induced migraine.

\section{IL-17A crosses BBB to trigger neuroinflammation in the TNC of rats with NTG-induced migraine NTG administration increased BBB permeability}

In the analysis of BBB-related proteins, the expression of RAGE/LRP1, a lipid transport functional protein, was inchoately increased after NTG injection. In contrast, the expression of AQP4/MFSD2A, an aqueous transport functional protein, was decreased (Fig. 8A, $\mathrm{C}-\mathrm{F})$. The structural proteins $\mathrm{ZO}-1$, Occludin and VE-cadherin-2 were maintained at high levels, probably due to compensation for persistent NTG injection (Fig. 8B, G-I). Live imaging was employed to record the fluorescence intensity of an impervious far-infrared probe (Cy5.5) in the rat brain at $4 \mathrm{~h}$ and dynamically observe changes in BBB permeability after NTG injection. The fluorescence intensity was remarkably increased from $30 \mathrm{~min}$ to $180 \mathrm{~min}$, and the peak fluorescence intensity was sustained from $45 \mathrm{~min}$ to $75 \mathrm{~min}$ after NTG injection, suggesting that the fast and transitory permeability generated by NTG might induce peripheral immune factor transport to the TNC (Fig. 8J-L). 


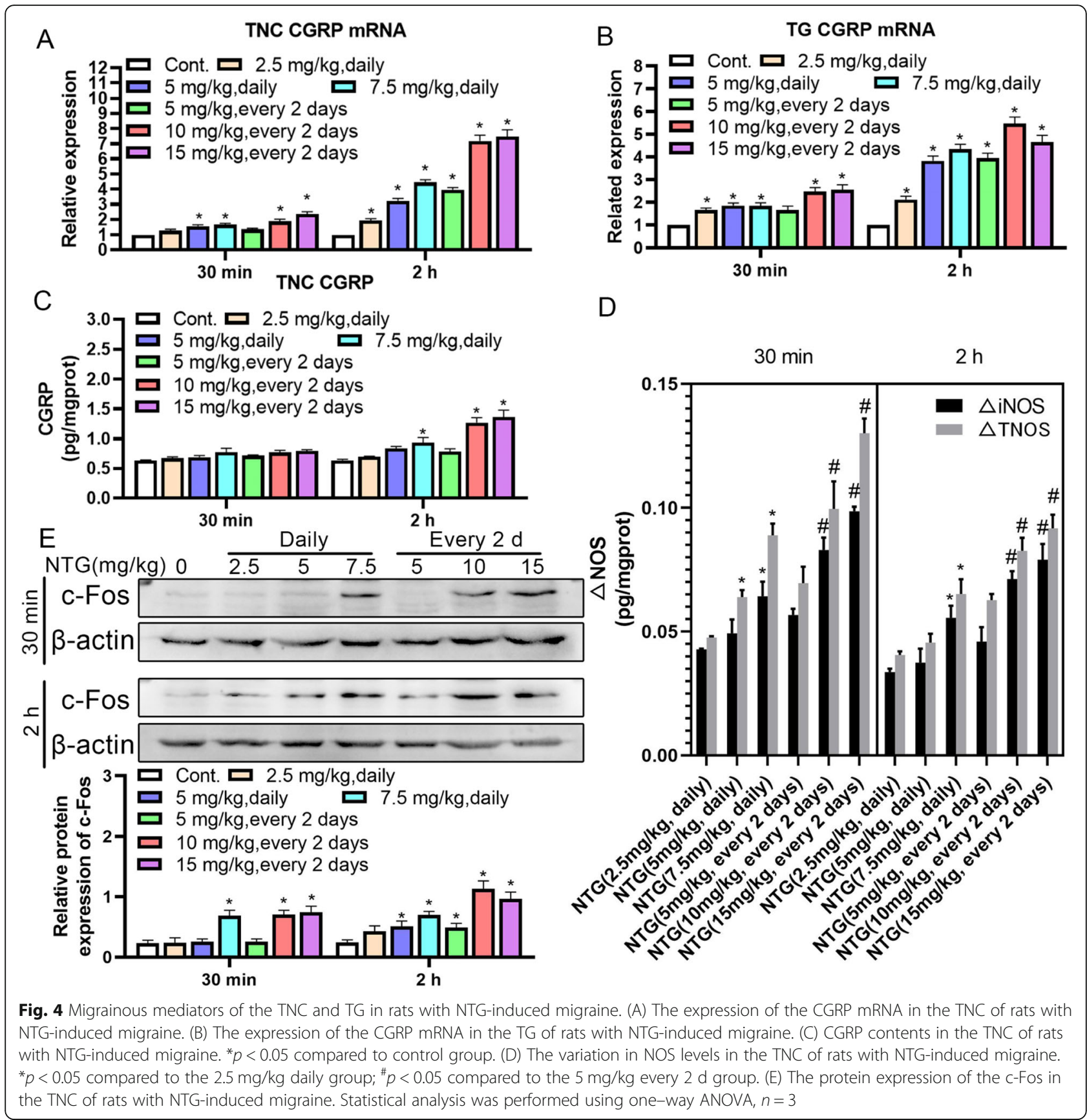

NTG-induced BBB alterations increased peripheral IL-17A access to the TNC

IL-17A has recently been at the forefront of neuroinflammation research. Emerging evidence indicates that IL-17A signals are the functional initiator of the inflammatory tendency of neurocytes [35, 51]. Interestingly, the IL-17A level was rapidly increased in the TNC and serum after NTG injection, whereas qRT-PCR data showed that IL-17A transcription was not initiated in TNC (Fig. 9A-D). In general, the region of TNC in MO possesses a relatively fragile $\mathrm{BBB}$. This evidence confirmed the hypothesis that NTG triggers neuroinflammation in the TNC by increasing the permeability of the $\mathrm{BBB}$ around the TNC, which promotes IL-17A transfer. EB staining assays showed that NTG increased the permeability of $\mathrm{EB}$ in the peripheral circulation and its transport to the TNC (Fig. 9E and F). Fluograms also revealed EB exudation from blood vessels, while $\mathrm{CD}_{4}{ }^{+}$/ IL-17A ${ }^{+} \mathrm{T}$ cells, an immune cell express IL-17A by reactivation, was not observed in the TNC (Fig. 8G and $\mathrm{H})$. IL-17A is involved in inducing the production of the cytokines IL-1 $\beta$, IL- 6 and TNF- $\alpha$. Previous ELISA results 


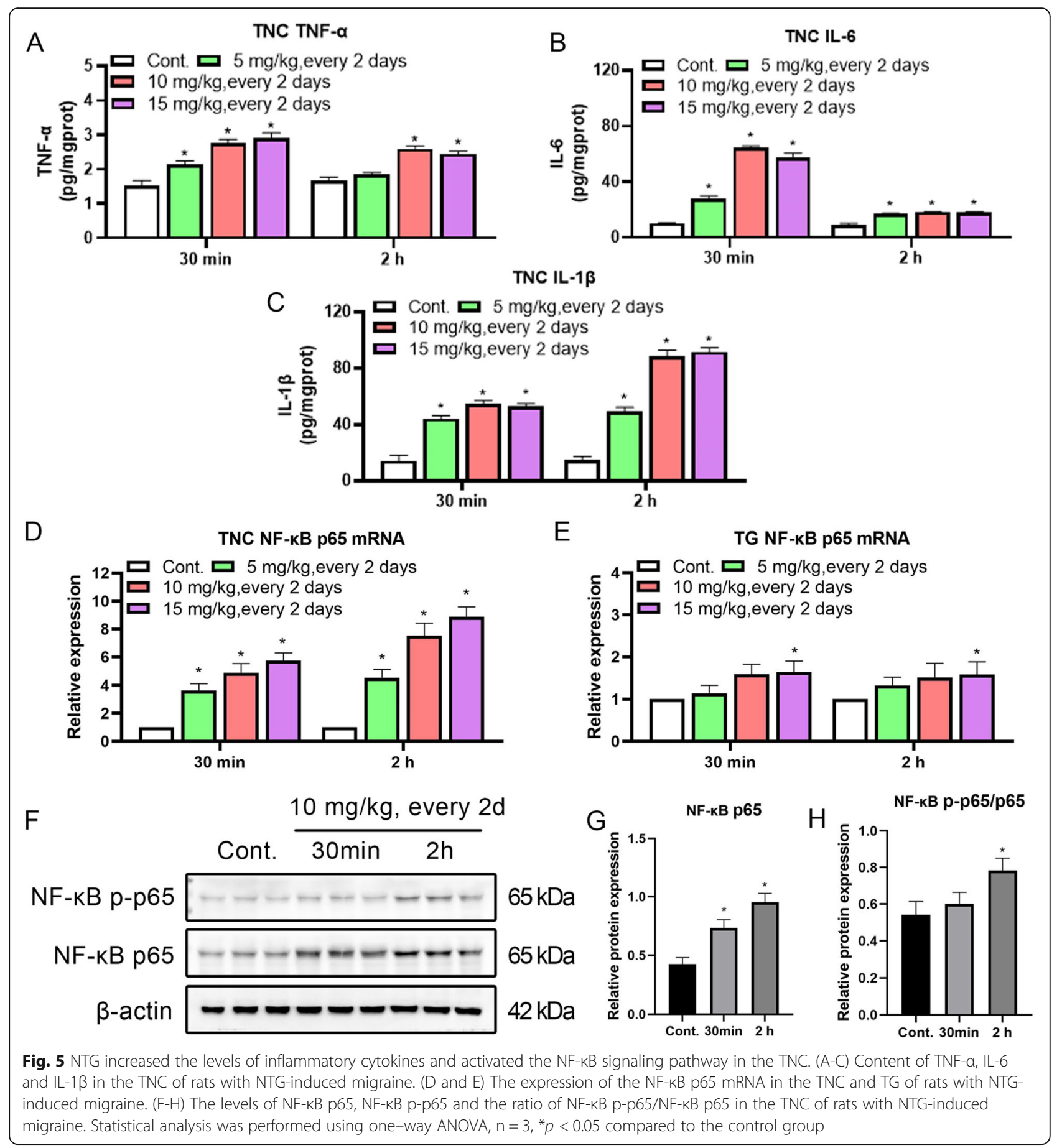

showed that IL-1 $\beta$, IL- 6 and TNF- $\alpha$ levels were also upregulated along with IL-17A (Fig. 5A-C), verifying that IL-17A triggered inflammation in the TNC. Collectively, NTG mediates the increase in BBB permeability around the MO to transfer IL-17A through the induction of the lipid transport function, neuroinflammation, and TNC activation, which is a novel mechanism of NTG-induced migraine that possibly bypasses the trigeminovascular system.

\section{Discussion}

In this study, we confirmed that NTG $(10 \mathrm{mg} / \mathrm{kg}$, s.c., every $2 \mathrm{~d}$ for a total of 5 times) was the optimal condition to provoke migraine that resulted in mechanical hyperalgesia and migraine-like behavior. Furthermore, NTG exerted a pharmacological effect on inducing neuroinflammation and enhancing TNC activation, in which IL-17A permeated the BBB from the periphery to potentially initiate the inflammatory polarization of microglia. 


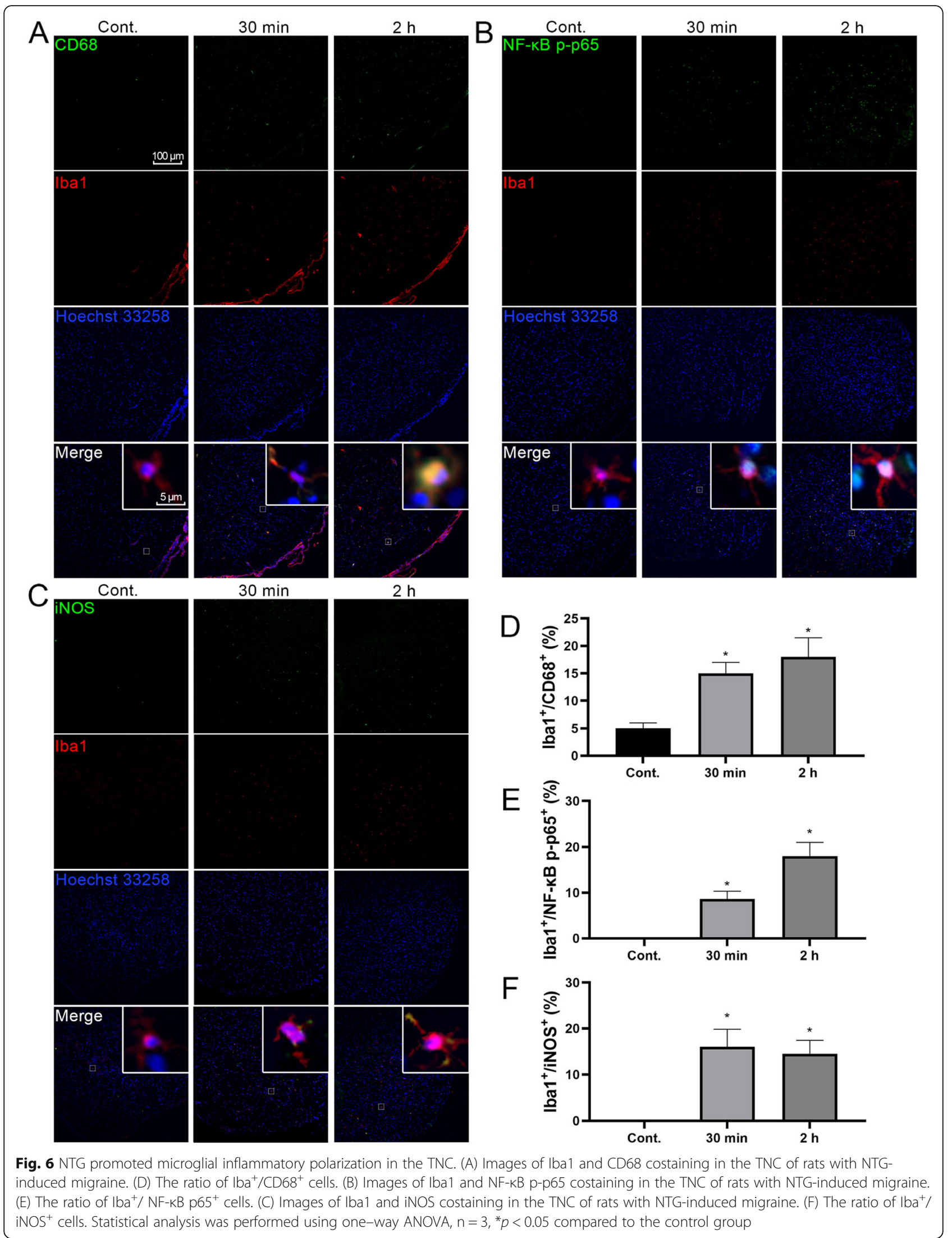




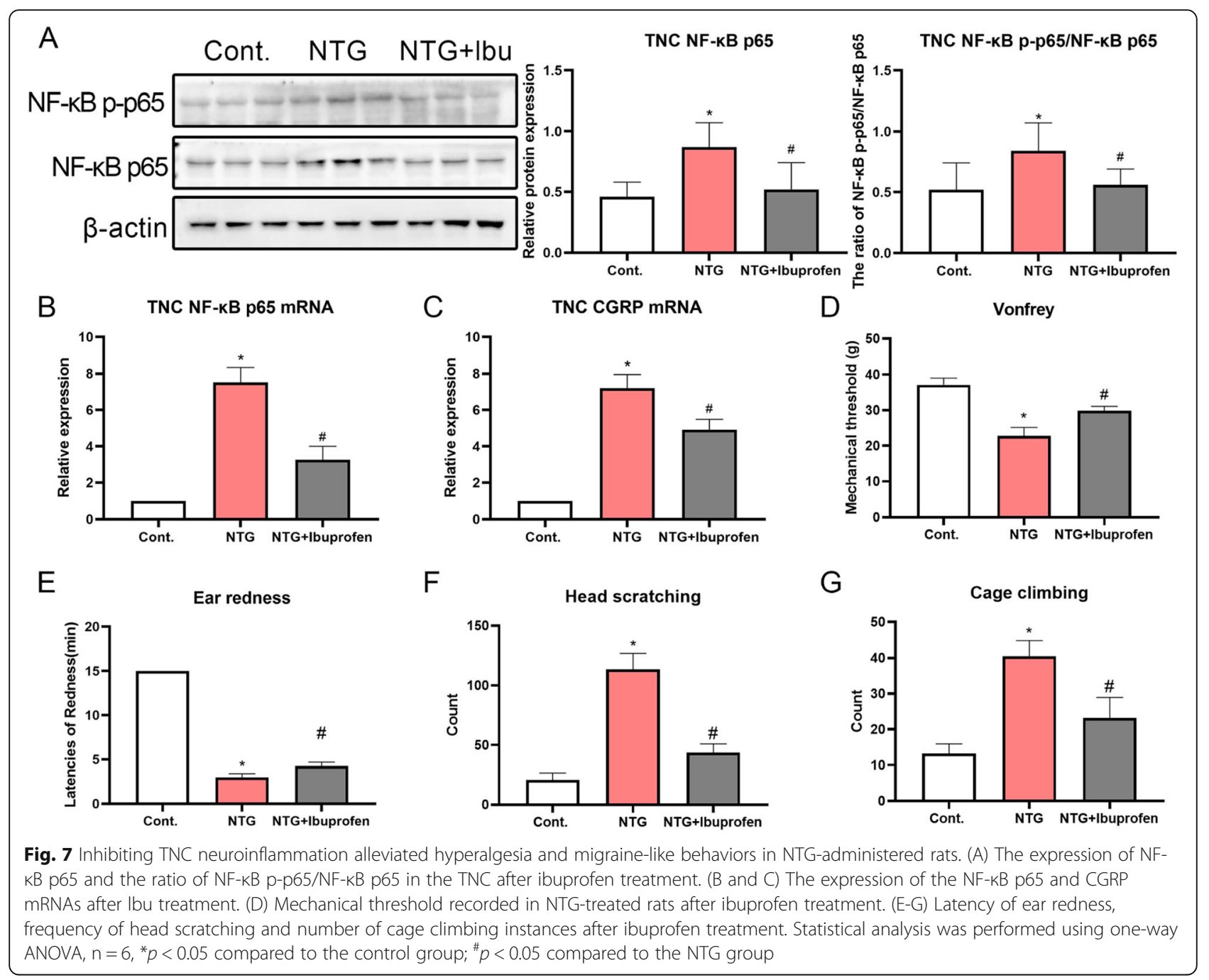

These findings provide support for the role of neuroinflammation in migraine. Additionally, IL-17A is a promising target involved in migraine and rats with NTGinduced migraine might serve as a useful neuroinflammatory tool to investigate the interventions for migraine, including an anti-IL-17A strategy and protection of the BBB.

The Global Burden of Disease Study ranked migraine as the seventh most common disabling pathology among 369 diseases, referred to as the 7th disabler [3]. Tools for modeling the characteristics of sensory sensitivity in patients with migraine are indispensable to elucidate pathophysiological mechanisms and identify novel therapies for chronic migraine. A number of promising models have been developed, such as the nitroglycerin (NTG) model, inflammatory soup model, trigeminal allodynia model and FHM1R192Q transgenic model, for migraine studies [46]. Relative to episodic migraine, CM is the most burdensome form and is associated with significantly greater disability, higher rates of comorbidity, and increased direct and indirect costs [34]. However, the progression of migraine from an episodic to a chronic disorder in an inflammatory soup model and a FHM1R192Q transgenic model has been particularly difficult to study. The observation of the behaviors in migraine attacks require a long period to collect. Operating difficulties and high costs also limited their application. Thus, chronic intermittent administration of NTG is a controllable and sustained method to model multiple acute migraine attacks.

When using the i.p. routes of administration, a very high dose of NTG is needed to induce behaviors comparable to that of human migraine, which may lead to intense visceral pain stimulation because of the inflammatory exudation induced by hemangiectasis [14]. As expected, the migraine behavior of rats was difficult to evaluate after multiple NTG i.p. injections since visceral pain (writhing and cramping reaction) masked the migraine behavior in our preliminary test. Therefore, s.c. injection is an alternative method of administration to 


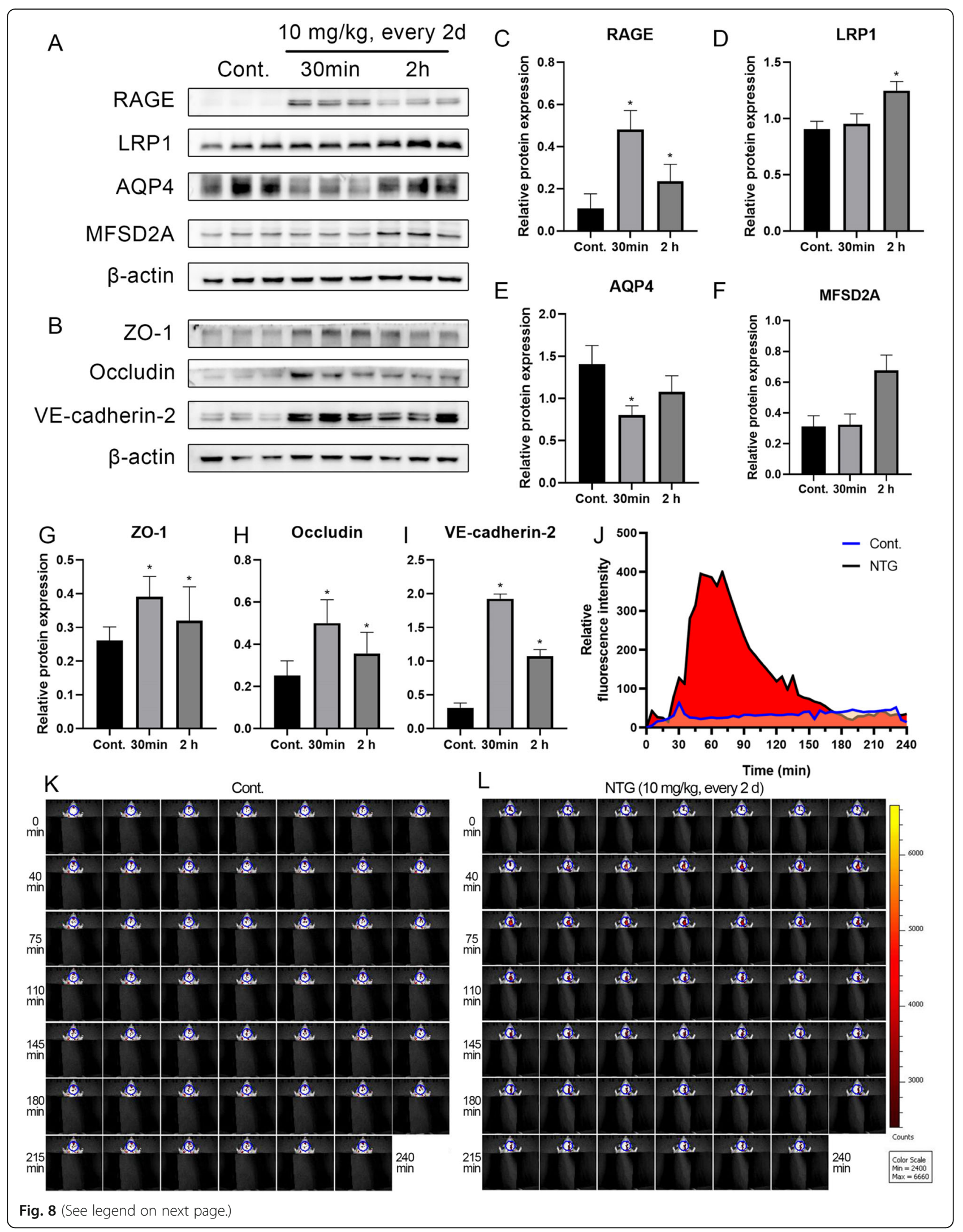


(See figure on previous page.)

Fig. 8 NTG administration increased BBB permeability. (A) NTG enhanced the transportation function of BBB. (C-F) The expression of RAGE, LRP1, AQP4 and MFSD2A in the TNC of rats with NTG-induced migraine. (B) NTG altered the structure of BBB. (G-I) The expression of ZO-1, Occludin and VE-cadherin-2 in the TNC of rats with NTG-induced migraine. (J-L) NTG increased the permeability of peripheral dye. After Cy5.5 circulation for $30 \mathrm{~min}$, NTG was subcutaneously injected. A live imaging system recorded the fluorescence signals at $695 \mathrm{~nm}$ for $4 \mathrm{~h}$ at $5 \mathrm{~min}$ intervals. Statistical analysis was performed using one-way ANOVA, $n=3,{ }^{*} p<0.05$ compared to the control group

establish the model of chronic migraine and avoid migraine nonaction due to visceral stimulation. On the other hand, although abundant reports have attested that a single dose of $5-15 \mathrm{mg} / \mathrm{kg}$ NTG in rodents has been extensively applied to induce adventitious migraine pain after a single treatment, systemic research on the features of sensation and behavior in rats resulting from repeated administration of these doses of NTG at the same intervals is lacking, which was convenient for researchers to choose a model that parallels clinical conditions and identify potential mechanisms of migraine. Thus, relatively wide range of NTG doses $(2.5-15 \mathrm{mg} /$ $\mathrm{kg})[5,39]$ has been administered daily or on an alternate schedule to SD rats for optimization based on the migraine reaction and behavior. According to previous reports, five injections of $5 \mathrm{mg} / \mathrm{kg}$ NTG were required to establish a rat model with migrainous allodynia [25]; a higher dose of NTG $(10 \mathrm{mg} / \mathrm{kg})$ led to hyperalgesia [24, 40]. In this study, threshold testing showed that all conditions induced dose-dependent mechanical hyperalgesia, consistent with the previous literature. Although the high-dose group and consecutive group showed a relatively stable and low basic threshold, the behaviors of head scratching and cage climbing in the high-dose group ( $15 \mathrm{mg} / \mathrm{kg}$ every $2 \mathrm{~d}$ and $7.5 \mathrm{mg} / \mathrm{kg}$ daily) were not as sensitive as those in the $10 \mathrm{mg} / \mathrm{mL}, 2 \mathrm{~d}$ group. Nongradual migraine behavior was also observed in the lowdose group. Furthermore, the baseline threshold in the interval administration groups showed a fluctuating decrease, which was possibly implicated in the obvious migraine behavior. An inappropriate delivery method and dose might explain why only threshold results were extensively observed in the majority of studies. Thus, 10 $\mathrm{mg} / \mathrm{kg}$ NTG administered s.c. every $2 \mathrm{~d}$ is a relatively optimized condition for establishing a model of chronic migraine in SD rats.

Dural neurogenic inflammation has been accepted as an important driver of migraine attacks for decades. Classic neurogenic inflammation is triggered by three main components, including the release CGRP and SP from meningeal afferent fibers, vasodilatation with plasma protein extravasation and meningeal mast cell degranulation [7, 9, 26, 29]. Another focus of migraine research has been the possible role of neurogenic neuroinflammation in a series of vital brain regions involved in migraine, including the thalamus, $\mathrm{MO}$ and cortex [19], although some inflammatory responses were not observed in a clinical trial [18]. In previous studies, the activation of neurogenic inflammation was indicated to be a crucial step in NTG-induced migraine attacks. Although the release of NO from NTG to activate its highaffinity receptor and trigger a cascade effect of cGMP leading to CGRP release is a well-accepted process by which NTG initiates neurogenic inflammation $[6,16]$, little evidence is available showing that meningeal neurogenic inflammation is the origin of genuine migraine attacks [18]. Recent fMRI data show that a migraine attack most likely originates in the hypothalamus and results in the activation of the MO [42]. In our rat model, the increases in CGRP and c-Fos levels revealed TNC activation. The NF- $\mathrm{KB}$ signaling cascade is involved in the upregulation of the migraine-related protein CGRP [54]. Thus, the increased levels of TNF- $\alpha$, IL- 6 and IL-1 $1 \beta$, the activation of NF- $\kappa B$ signaling and polarized microglia indicated that neurogenic neuroinflammation contributes to TNC activation, suggesting that NTG might trigger an upstream mechanism in which neuroinflammation is involved in mediating migraine attack. Our further observations that NTG-induced neuroinflammation are blocked by ibuprofen is supported by similar outcomes in which NTG-induced hyperalgesia is abolished by the administration of nimesulide (a COX-2 inhibitor) both in animal and human studies [50]. This evidence suggests that neurogenic neuroinflammation characterized by increased CGRP and c-Fos levels is a compelling feature of the NTG model, which identified the fields of application of this model to test novel antiphlogistic or anti-CGRP therapies in individuals with migraine.

IL-17A is one of the most frequently investigated cytokines in IL-17 family, and it mediates the communication between immune cells and tissue. According to recent investigations, IL-17A plays a pivotal role in neuroinflammation [51]. Our observations showed that NTG increased IL-17A levels both in periphery and MO, which indicated that IL-17A might initiate NTGinduced neuroinflammation. Little evidence is available that cells other than immune cells express IL-17A. As a rule, immune cells express IL-17A and IL-17F, and tissue cells, such as keratinocytes in the skin, epidermal cells in the gut or glial cells in the CNS, respond to it [37]. In addition to cells in the peripheral immune system, microglia was also a cell type that responds to IL$17 \mathrm{~A}$ through the NF- $\mathrm{KB}$ pathway during 


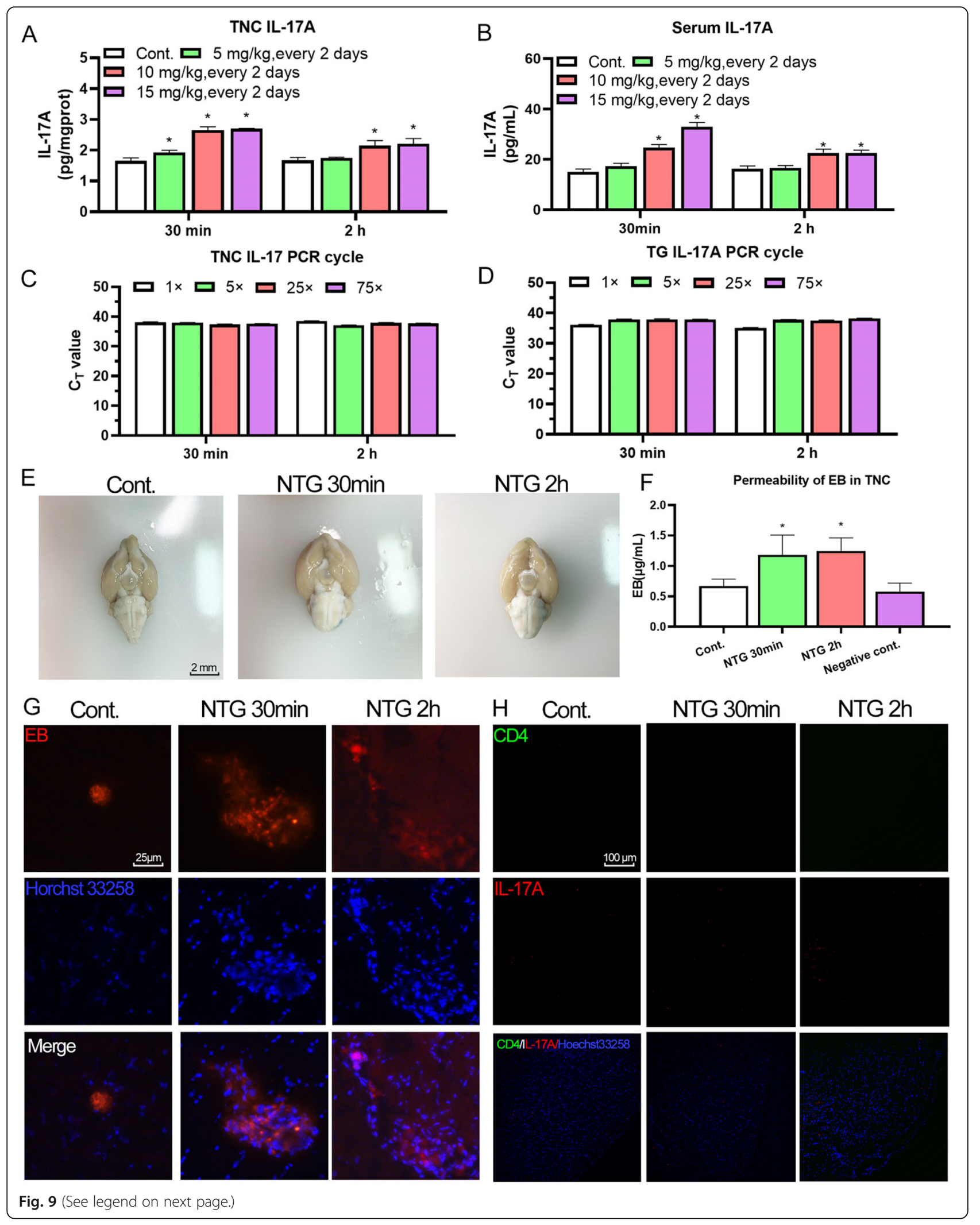


(See figure on previous page.)

Fig. 9 NTG-induced BBB alterations increased peripheral IL-17A access to the TNC. NTG administration increased IL-17A levels, while its transcription was not initiated in the TNC. (A and B) Content of IL-17A in the TNC and serum of rats with NTG-induced migraine. (C and D) The Ct value of the IL-17A mRNA in the TNC and TG of rats with NTG-induced migraine. NTG administration altered BBB permeability. (E) Bright-field image of EB permeation in rats with NTG-induced migraine. (F) EB permeability in the TNC of rats with NTG-induced migraine. (G) Images of EB staining in the TNC of rats with NTG-induced migraine. NTG administration did not induce $\mathrm{CD}_{4}{ }^{+} / \mathrm{IL}-17 \mathrm{~A}^{+} \mathrm{T}$ cell migration into the TNC. (H) Images of $\mathrm{CD}_{4}$ and IL-17A co-staining in rats with NTG-induced migraine. Statistical analysis was performed using one-way ANOVA, $\mathrm{n}=3,{ }^{*} p<0.05$ compared to the control group

neuroinflammation, such as multiple sclerosis [23]. The transcription of IL-17A in the TNC and TG was detected to investigate its source. Interestingly, the extremely high $\mathrm{Ct}$ value of IL-17A indicated a lack of IL17A expression in the TNC and TG. In CNS autoimmunity, $\mathrm{CD}_{4}{ }^{+} \mathrm{T}$ cells enter the subarachnoid space by crossing the blood-cerebrospinal fluid barrier and are reactivated by macrophages and dendritic cells into $\mathrm{IL}^{+} 7^{+} \mathrm{T}$ cells $[23,31]$. We thus speculated that reactivated $\mathrm{CD}_{4}{ }^{+} \mathrm{T}$ cells and peripheral IL-17A permeation are the potential sources of IL-17A in the CNS. Thus, we further monitored the BBB permeability by injecting an impermeable dye and measured the levels of BBBrelated proteins. The results proved that NTG increased $\mathrm{BBB}$ permeability in the $\mathrm{MO}$, while $\mathrm{CD}_{4}{ }^{+} / \mathrm{IL}_{17}{ }^{+} \mathrm{T}$ cells were not observed in the MO. The MO is a region with a relatively weak $\mathrm{BBB}$ and enhances biochemical delivery [2]. Therefore, these findings confirmed the mechanism that the integrity of the BBB was altered by NTG or CGRP; subsequently, IL-17A derived from periphery induced neuroinflammation and hypersensitization in the TNC, which gain a deep insight to the IL-17A inflammatory signaling in NTG-induced migraine and revealed that anti-inflammation or BBB protection strategy warrant further research to investigate the availability in clinical treatment.

\section{Conclusions}

In summary, this study optimized and screened the conditions for establishing a chronic migraine model in rats. NTG $(10 \mathrm{mg} / \mathrm{kg}$, s.c., every $2 \mathrm{~d}$ for a total of 5 injections) was confirmed to provoke migraine resulting in mechanical hyperalgesia and migraine-like behavior. Moreover, neuroinflammation is a characteristic of the NTGtreated model, which can be alleviated by ibuprofen, suggesting that this model is capable of serving as a screening tool for migraine agents with potential antiinflammatory activity. In terms of pathogenic mechanisms, NTG triggers CGRP-associated neuroinflammation by increasing BBB permeability and inducing the inflammatory polarization of microglia owing to IL-17A infiltration into the MO. These changes eventually lead to mechanical hyperalgesia and migrainous attack through TNC activation (Fig. 10).

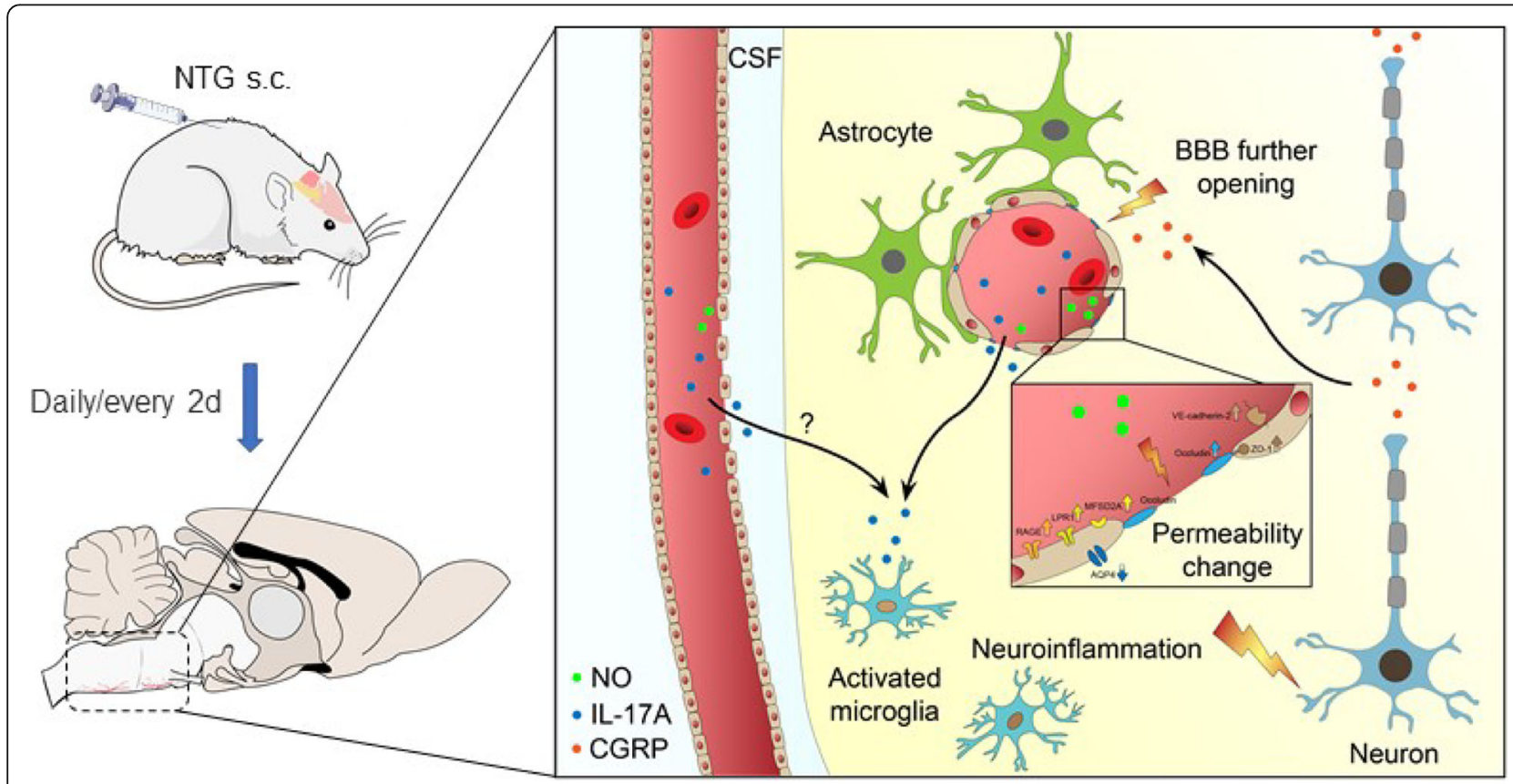

Fig. 10 Peripheral IL-17A crosses BBB into MO with TNC to trigger neuroinflammation in rats with NTG-induced migraine 


\section{Abbreviations}

NTG: Nitroglycerin; TNC: Nucleus caudate of trigeminal nerve; TG: Trigeminal ganglion; MO: Medulla oblongata; CGRP: Essential oil from Eupatorium odoratum L; NF-kB: Nuclear factor kappa-light-chain-enhancer of activated B cells; IL-17A: Interleukin-17A; i.p: Intraperitoneal injection; s.c: Subcutaneous injection; BBB: Blood-brain barrier

\section{Authors' contributions}

SJX conceived, designed the study and critically reviewed, edited, and revised the paper; $\mathrm{HC}$ performed the main research and wrote the original manuscript. XQT performed the data statistics. JL performed the western blot. BYH manage the project fund. WQY, MZ and TYM performed behavioral and threshold testing. All authors read and approved the final manuscript.

\section{Funding}

The work was supported by The National Key Research and Development Program of China (NO.2019YFC1709704) and The Open Research Fund of Chengdu University of Traditional Chinese Medicine Key Laboratory of Systematic Research of Distinctive Chinese Medicine Resources in Southwest China (2020XSGG005).

\section{Availability of data and materials}

The datasets used and analyzed in the present study are available from the corresponding author on reasonable request.

\section{Declarations}

\section{Ethics approval and consent to participate}

The IRB of the Institute of Materia Medica Integration and Transformation for Brain Disorders, Chengdu University of Traditional Chinese Medicine have approved this study. All participants have provided written informed consent to participate.

\section{Consent for publication}

Not applicable.

\section{Competing interests}

The authors have no conflict of interest exits regarding the contents of the manuscript.

\section{Author details}

'School of Pharmacy, Chengdu University of Traditional Chinese Medicine, Chengdu, Sichuan 611137, People's Republic of China. Institute of Meterial Medica Integration and Transformation for Brain Disorders, Chengdu University of Traditional Chinese Medicine, Chengdu, Sichuan 611137, People's Republic of China. ${ }^{3}$ State Key Laboratory of Southwestern Chinese Medicine Resources, Chengdu, Sichuan 611137, People's Republic of China.

Received: 29 August 2021 Accepted: 15 December 2021

Published online: 03 January 2022

\section{References}

1. Albrecht DS, Mainero C, Ichijo E, Ward N, Granziera C, Zürcher NR, Akeju O, Bonnier G, Price J, Hooker JM, Napadow V, Loggia ML, Hadjikhani N (2019) Imaging of neuroinflammation in migraine with aura: a [(11) C]PBR28 PET/ MRI study. Neurology 92(17):e2038-e2050. https://doi.org/10.1212/wnl. 0000000000007371

2. Alli S, Figueiredo CA, Golbourn B, Sabha N, Wu MY, Bondoc A, Luck A, Coluccia D, Maslink C, Smith C, Wurdak H, Hynynen K, O'Reilly M, Rutka JT (2018) Brainstem blood brain barrier disruption using focused ultrasound: a demonstration of feasibility and enhanced doxorubicin delivery. J Control Release 281:29-41. https://doi.org/10.1016/j.jconrel.2018.05.005

3. Anonymous (2020) Five insights from the global burden of disease study 2019. Lancet 396(10258):1135-1159. https://doi.org/10.1016/s0140-6736(2 0)31404-5

4. Ashina M (2020) Migraine. N Engl J Med 383(19):1866-1876. https://doi. org/10.1056/NEJMra1915327

5. Bates EA, Nikai T, Brennan KC, Fu YH, Charles AC, Basbaum Al, Ptáček $\amalg$, Ahn AH (2010) Sumatriptan alleviates nitroglycerin-induced mechanical and thermal allodynia in mice. Cephalalgia 30(2):170-178. https://doi.org/1 0.1111/j.1468-2982.2009.01864.x
6. Burstein R, Noseda R, Borsook D (2015) Migraine: multiple processes, complex pathophysiology. J Neurosci 35(17):6619-6629. https://doi.org/10.1 523/jneurosci.0373-15.2015

7. Casili G, Lanza M, Filippone A, Campolo M, Paterniti I, Cuzzocrea S, Esposito E (2020) Dimethyl fumarate alleviates the nitroglycerin (NTG)-induced migraine in mice. J Neuroinflammation 17(1):59. https://doi.org/10.1186/s12 974-020-01736-1

8. Cavestro C, Ferrero M, Mandrino S, di Tavi M, Rota E (2019) Novelty in inflammation and immunomodulation in migraine. Curr Pharm Des 25(27): 2919-2936. https://doi.org/10.2174/1381612825666190709204107

9. Cetinkaya A, Kilinc E, Camsari C, Ogun MN (2020) Effects of estrogen and progesterone on the neurogenic inflammatory neuropeptides: implications for gender differences in migraine. Exp Brain Res 238(11):2625-2639. https:// doi.org/10.1007/s00221-020-05923-7

10. Chanda ML, Tuttle AH, Baran I, Atlin C, Guindi D, Hathaway G, Israelian N, Levenstadt J, Low D, Macrae L, O'Shea L, Silver A, Zendegui E, Lenselink MA, Spijker S, Ferrari MD, van den Maagdenberg AMJM, Mogil JS (2013) Behavioral evidence for photophobia and stress-related ipsilateral head pain in transgenic Cacna1a mutant mice. Pain 154(8):1254-1262. https://doi.org/1 0.1016/j.pain.2013.03.038

11. Chen H, Pan T, Liu P, Wang P, Xu S (2019) Baihu Jia Guizhi decoction improves rheumatoid arthritis inflammation by regulating succinate/ SUCNR1 metabolic signaling pathway. Evid Based Complement Alternat Med 2019:3258572. https://doi.org/10.1155/2019/3258572

12. Chou TM, Chen SP (2018) Animal models of chronic migraine. Curr Pain Headache Rep 22(6):44. https://doi.org/10.1007/s1 1916-018-0693-5

13. Covelli V, Munno I, Pellegrino NM, Altamura M, Decandia P, Marcuccio C, di Venere A, Jirillo E (1991) Are TNF-alpha and IL-1 beta relevant in the pathogenesis of migraine without aura? Acta Neurol (Napoli) 13(2):205-211

14. Demartini C, Greco R, Zanaboni AM, Sances G, de Icco R, Borsook D, Tassorelli C (2019) Nitroglycerin as a comparative experimental model of migraine pain: from animal to human and back. Prog Neurobiol 177:15-32. https://doi.org/10.1016/j.pneurobio.2019.02.002

15. Diehl KH, Hull R, Morton D, Pfister R, Rabemampianina Y, Smith D, Vidal JM, van de Vorstenbosch C, European Federation of Pharmaceutical Industries Association and European Centre for the Validation of Alternative Methods (2001) A good practice guide to the administration of substances and removal of blood, including routes and volumes. J Appl Toxicol 21(1):15-23. https://doi.org/10.1002/jat.727

16. Dodick DW (2018) A phase-by-phase review of migraine pathophysiology. Headache 58(Suppl 1):4-16. https://doi.org/10.1111/head.13300

17. Duarte-Delgado NP, Vásquez G, Ortiz-Reyes BL (2019) Blood-brain barrier disruption and neuroinflammation as pathophysiological mechanisms of the diffuse manifestations of neuropsychiatric systemic lupus erythematosus. Autoimmun Rev 18(4):426-432. https://doi.org/10.1016/j.a utrev.2018.12.004

18. Edvinsson L, Haanes KA, Warfvinge K (2019) Does inflammation have a role in migraine? Nat Rev Neurol 15(8):483-490. https://doi.org/10.1038/s41582019-0216-y

19. Erdener ŞE, Kaya Z, Dalkara T (2021) Parenchymal neuroinflammatory signaling and dural neurogenic inflammation in migraine. J Headache Pain 22(1):138. https://doi.org/10.1186/s10194-021-01353-0

20. Faraco G, Brea D, Garcia-Bonilla L, Wang G, Racchumi G, Chang H, Buendia I, Santisteban MM, Segarra SG, Koizumi K, Sugiyama Y, Murphy M, Voss H, Anrather J, ladecola C (2018) Dietary salt promotes neurovascular and cognitive dysfunction through a gut-initiated TH17 response. Nat Neurosci 21(2):240-249. https://doi.org/10.1038/s41593-017-0059-z

21. Gautam M, Ramanathan M (2021) Ameliorative potential of flavonoids of Aegle marmelos in vincristine-induced neuropathic pain and associated excitotoxicity. Nutr Neurosci 24(4):296-306. https://doi.org/10.1080/102841 $5 \times .2019 .1627768$

22. Giesen J, Füchtbauer EM, Füchtbauer A, Funke K, Koesling D, Russwurm M (2020) AMPA induces NO-dependent CGMP signals in hippocampal and cortical neurons via L-type voltage-gated calcium channels. Cereb Cortex 30(4):2128-2143. https://doi.org/10.1093/cercor/bhz227

23. Goverman J (2009) Autoimmune T cell responses in the central nervous system. Nat Rev Immunol 9(6):393-407. https://doi.org/10.1038/nri2550

24. Greco R, Demartini C, Zanaboni A, Casini I, de Icco R, Reggiani A, Misto A, Piomelli D, Tassorelli C (2021) Characterization of the peripheral FAAH inhibitor, URB937, in animal models of acute and chronic migraine. Neurobiol Dis 147:105157. https://doi.org/10.1016/j.nbd.2020.105157 
25. Greco R, Demartini C, Zanaboni AM, Tassorelli C (2018) Chronic and intermittent administration of systemic nitroglycerin in the rat induces an increase in the gene expression of CGRP in central areas: potential contribution to pain processing. J Headache Pain 19(1):51. https://doi.org/1 0.1186/s10194-018-0879-6

26. Guo Z, Czerpaniak K, Zhang J, Cao YQ (2021) Increase in trigeminal ganglion neurons that respond to both calcitonin gene-related peptide and pituitary adenylate cyclase-activating polypeptide in mouse models of chronic migraine and posttraumatic headache. Pain 162(5):1483-1499. https://doi.org/10.1097/j.pain.0000000000002147

27. Juhasz G, Zsombok T, Jakab B, Nemeth J, Szolcsanyi J, Bagdy G (2005) Sumatriptan causes parallel decrease in plasma calcitonin gene-related peptide (CGRP) concentration and migraine headache during nitroglycerin induced migraine attack. Cephalalgia 25(3):179-183. https://doi.org/10.1111/ j.1468-2982.2005.00836.x

28. Kilinc E, Ankarali S, Torun IE, Dagistan Y (2020) Receptor mechanisms mediating the anti-neuroinflammatory effects of endocannabinoid system modulation in a rat model of migraine. Eur J Neurosci. https://doi.org/1 0.1111/ejn.14897

29. Kilinc E, Tore F, Dagistan Y, Bugdayci G (2020) Thymoquinone inhibits neurogenic inflammation underlying migraine through modulation of calcitonin gene-related peptide release and stabilization of meningeal mast cells in Glyceryltrinitrate-induced migraine model in rats. Inflammation 43(1): 264-273. https://doi.org/10.1007/s10753-019-01115-w

30. Knapp L, Szita B, Kocsis K, Vécsei L, Toldi J (2017) Nitroglycerin enhances the propagation of cortical spreading depression: comparative studies with sumatriptan and novel kynurenic acid analogues. Drug Des Devel Ther 11: 27-34. https://doi.org/10.2147/dddt.s117166

31. Korn T, Kallies A (2017) T cell responses in the central nervous system. Nat Rev Immunol 17(3):179-194. https://doi.org/10.1038/nri.2016.144

32. Koyuncu Irmak D, Kilinc E, Tore F (2019) Shared fate of meningeal mast cells and sensory neurons in migraine. Front Cell Neurosci 13:136. https://doi. org/10.3389/fncel.2019.00136

33. Li Y, Zhang Q, Qi D, Zhang L, Yi L, Li Q, Zhang Z (2016) Valproate ameliorates nitroglycerin-induced migraine in trigeminal nucleus caudalis in rats through inhibition of NF-kB. J Headache Pain 17(1):49. https://doi.org/1 0.1186/s10194-016-0631-z

34. Lipton RB, Goadsby PJ, Smith J, Schaeffler BA, Biondi DM, Hirman J, Pederson S, Allan B, Cady R (2020) Efficacy and safety of eptinezumab in patients with chronic migraine: PROMISE-2. Neurology 94(13):e1365-e1377. https://doi.org/10.1212/wnl.0000000000009169

35. Liu Z, Qiu AW, Huang Y, Yang Y, Chen JN, Gu TT, Cao BB, Qiu YH, Peng YP (2019) IL-17A exacerbates neuroinflammation and neurodegeneration by activating microglia in rodent models of Parkinson's disease. Brain Behav Immun 81:630-645. https://doi.org/10.1016/j.bbi.2019.07.026

36. Long T, He W, Pan Q, Zhang S, Zhang D, Qin G, Chen L, Zhou J (2020) Microglia P2X4R-BDNF signalling contributes to central sensitization in a recurrent nitroglycerin-induced chronic migraine model. J Headache Pain 21(1):4. https://doi.org/10.1186/s10194-019-1070-4

37. Mcgeachy MJ, Cua DJ, Gaffen SL (2019) The IL-17 family of cytokines in health and disease. Immunity 50(4):892-906. https://doi.org/10.1016/j. immuni.2019.03.021

38. Niu J, Tsai HH, Hoi KK, Huang N, Yu G, Kim K, Baranzini SE, Xiao L, Chan JR, Fancy SPJ (2019) Aberrant oligodendroglial-vascular interactions disrupt the blood-brain barrier, triggering CNS inflammation. Nat Neurosci 22(5):709718. https://doi.org/10.1038/s41593-019-0369-4

39. Nozaki C, Markert A, Zimmer A (2015) Inhibition of FAAH reduces nitroglycerin-induced migraine-like pain and trigeminal neuronal hyperactivity in mice. Eur Neuropsychopharmacol 25(8):1388-1396. https:// doi.org/10.1016/j.euroneuro.2015.04.001

40. Pradhan AA, Smith ML, Mcguire B et al (2014) Characterization of a novel model of chronic migraine. Pain 155(2):269-274. https://doi.org/10.1016/j.pa in.2013.10.004

41. Sances G, Tassorelli C, Pucci E, Ghiotto N, Sandrini G, Nappi G (2004) Reliability of the nitroglycerin provocative test in the diagnosis of neurovascular headaches. Cephalalgia 24(2):110-119. https://doi.org/1 0.1111/j.1468-2982.2004.00639.x

42. Schulte LH, Allers A, May A (2017) Hypothalamus as a mediator of chronic migraine: evidence from high-resolution fMRI. Neurology 88(21):2011-2016. https://doi.org/10.1212/wnl.0000000000003963
43. Schulte LH, May A (2016) The migraine generator revisited: continuous scanning of the migraine cycle over 30 days and three spontaneous attacks. Brain 139(7):1987-1993. https://doi.org/10.1093/brain/aww097

44. Sufka KJ, Staszko SM, Johnson AP, Davis ME, Davis RE, Smitherman TA (2016) Clinically relevant behavioral endpoints in a recurrent nitroglycerin migraine model in rats. J Headache Pain 17(1):40. https://doi.org/10.1186/s1 0194-016-0624-y

45. Sulhan S, Lyon KA, Shapiro LA, Huang JH (2020) Neuroinflammation and blood-brain barrier disruption following traumatic brain injury: pathophysiology and potential therapeutic targets. J Neurosci Res 98(1):1928. https://doi.org/10.1002/jnr.24331

46. Tardiolo G, Bramanti P, Mazzon E (2019) Migraine: experimental models and novel therapeutic approaches. Int J Mol Sci 20(12). https://doi.org/10.3390/ ijms20122932

47. Tasleem F, Azhar I, Ali SN et al (2014) Analgesic and anti-inflammatory activities of Piper nigrum L. Asian Pac J trop med 7s1:S461-468. https://doi. org/10.1016/s1995-7645(14)60275-3

48. Turksen K (2011) Permeability barrier. Humana Press. https://doi.org/10.1007/ 978-1-61779-191-8

49. Van Vliet EA, Ndode-Ekane XE, Lehto $\amalg$ et al (2020) Long-lasting bloodbrain barrier dysfunction and neuroinflammation after traumatic brain injury. Neurobiol Dis 145:105080. https://doi.org/10.1016/..nbd.2020.105080

50. Vellani V, Moschetti G, Franchi S, Giacomoni C, Sacerdote P, Amodeo G (2017) Effects of NSAIDs on the release of calcitonin gene-related peptide and prostaglandin E (2) from rat trigeminal ganglia. Mediat Inflamm 2017: 9547056. https://doi.org/10.1155/2017/9547056

51. Waisman A, Hauptmann J, Regen T (2015) The role of IL-17 in CNS diseases. Acta Neuropathol 129(5):625-637. https://doi.org/10.1007/s00401-015-14027

52. Warfvinge K, Edvinsson $L$ (2019) Distribution of CGRP and CGRP receptor components in the rat brain. Cephalalgia 39(3):342-353. https://doi.org/1 $0.1177 / 0333102417728873$

53. Wen W, Chen H, Fu K, Wei J, Qin L, Pan T, Xu S (2020) Fructus Viticis methanolic extract attenuates trigeminal hyperalgesia in migraine by regulating injury signal transmission. Exp Ther Med 19(1):85-94. https://doi. org/10.3892/etm.2019.8201

54. Yao G, Man YH, Li AR et al. (2020) NO up-regulates migraine-related CGRP via activation of an Akt/GSK-3//NF-KB signaling cascade in trigeminal ganglion neurons. Aging 12:6370-6384. https://doi.org/10.18632/aging.103 031

55. Zhang S, Hu L, Jiang J, Li H, Wu Q, Ooi K, Wang J, Feng Y, Zhu D, Xia C (2020) HMGB1/RAGE axis mediates stress-induced RVLM neuroinflammation in mice via impairing mitophagy flux in microglia. J Neuroinflammation 17(1):15. https://doi.org/10.1186/s12974-019-1673-3

\section{Publisher's Note}

Springer Nature remains neutral with regard to jurisdictional claims in published maps and institutional affiliations.

\section{Ready to submit your research? Choose BMC and benefit from:}

- fast, convenient online submission

- thorough peer review by experienced researchers in your field

- rapid publication on acceptance

- support for research data, including large and complex data types

- gold Open Access which fosters wider collaboration and increased citations

- maximum visibility for your research: over $100 \mathrm{M}$ website views per year

At BMC, research is always in progress.

Learn more biomedcentral.com/submission 